\title{
Voor en na epilepsiechirurgie: achterstand in sociale
} ontwikkeling

Olga Braams promoveerde op 9 mei 2019 aan de Universiteit Utrecht op het proefschrift Social matters. Before and after epilepsy surgery in children ${ }^{\mathrm{I}}$. In haar onderzoek werden de volgende vragen gesteld, die ten grondslag liggen aan dit proefschrift. Was de operatie een kantelpunt in de ontwikkeling van sociaal functioneren, als basis van cognitieve maar ook affectieve ontwikkeling? Konden bepalende invloeden vastgesteld worden?

Dit proefschrift is de afsluiting van een landelijk onderzoeksprogramma. Centrale vraag was of de hersenoperatie 'goed' voor de aanvallen maar schadelijk voor de ontwikkeling zou kunnen zijn. Het protocol had twee belangrijke pijlers: consecutieve patiënteninclusie en preoperatief uitgangsonderzoek waartegen het postoperatieve verloop werd afgezet. De reeks studies van onder andere motoriek, visuele waarneming, intelligentie, geheugen, taal en sociaal functioneren verschafte een rijkdom aan kennis.

\section{De onderzoekspopulatie}

Tussen januari 2008 en december 2010 oordeelde de Landelijke Werkgroep Epilepsiechirurgie 68 kinderen in de leeftijd van o tot I8 jaar geschikt voor epilepsiechirurgie (callosotomie uitgezonderd). Deze kinderen vormden het cohort voor longitudinaal onderzoek van sociale cognitie en persoonlijkheid. Uit een groot bestand van controlekandidaten werden direct na inclusie van een patiënt, twee zich normaal ontwikkelende gezonde leeftijdgenoten van hetzelfde geslacht als de patiënt opgeroepen. Elk drietal werd vier maal onderzocht: de patiënten kort voor operatie en 6, I2 en 24 maanden daarna en de controlekinderen met dezelfde tijdsintervallen. De ouders van de deelnemende kinderen vulden vragenlijsten in waaruit een belangrijke gezinsinvloed werd afgeleid: hun stress bij het opvoeden van dit kind. Ouderparen van het cohort tussen juni 2010 en juni 2012 geopereerde kinderen evalueerden twee tot vier jaar na epilepsiechirurgie, eenmalig hun eigen psychische functioneren en het functioneren van hun gezin.

\section{Methode van onderzoek}

De kinderen kregen voor hun leeftijd c.q. ontwikkeling geschikte tests aangeboden. Sommige tests werden dus gemaakt door weinig kinderen, met als gevolg dat de statistische zoektocht naar de kracht van de vele invloeden een exploratief karakter had. Leeftijd van epilepsiebegin, duur van de epilepsie, plaats van de epileptogene zone, al dan niet resectie van de amygdala en etiologie waren de geëxploreerde klinische invloeden; geslacht en leeftijd de demografische invloeden. In de analyses werd gecontroleerd voor de verbale intelligentie van de kinderen omdat de tests een beroep deden op taalgebruik. Multivariate analysetechnieken maakten correctie voor veelvuldig statistisch toetsen overbodig.

Van de variabele 'sociale cognitie' oftewel de mentale processen nodig voor waarnemen en verwerken van sociale informatie, onderzocht Braams een basale component (het herkennen van emotionele gelaatsuitdrukkingen) en een hogere component (theory of mind: mentale toestanden zoals meningen, bedoelingen, wensen, voorwendsels en kennis toeschrijven aan anderen en aan jouzelf en begrijpen dat anderen niet altijd hetzelfde denken en voelen als jijzelf). Theory of mind (ToM) werd uitgedrukt in een quotient (ToM-Q). De epilepsiegroep scoorde preoperatief gemiddeld lager dan de controlegroep op hetzelfde onderzoekmoment. Epilepsiechirurgie bracht geen significante verschuiving in het ToM-Q. Herkennen van gelaatsuitdrukkingen was voor kinderen met epilepsie twee jaar na operatie moeilijker dan voor gezonde leeftijdgenoten (N.B. de desbetreffende test kwam later dan verwacht beschikbaar, waardoor preoperatieve bepaling ontbrak).

\section{Ervaringen van kind en ouders}

De kinderen vulden zelf een persoonlijkheidsvragenlijst

${ }^{1}$ Promotor: Prof. dr. K.P.J. Braun, copromotor: Dr R. Schappin. Geïnitieerd en mede begeleid door auteurs van dit stuk. 
in. Kinderen met epilepsie beschreven bij zichzelf meer vage angsten, somberheid en gebrek aan zelfvertrouwen, alsook meer teruggetrokkenheid en verlegenheid dan controlekinderen; ze hadden een sterkere neiging tot zich afzetten tegen anderen en tot ik-gericht gedrag. Maar ze hadden ook meer volharding. Deze eigenschappen, teruggetrokkenheid en verlegenheid verbeterden na de operatie.

Ouders van kinderen met refractaire epilepsie ervoeren meer opvoedingsstress dan ouders van gezonde leeftijdgenoten. Twee jaar later was de stress in beide groepen weliswaar evenveel verminderd, maar was bij de ouders van de inmiddels geopereerde patiëntjes niet genormaliseerd. Bij ouders van afleidbare/hyperactieve kinderen en van aanvalsvrij geworden kinderen was de stress wel duidelijk gedaald.

Het eigen psychisch functioneren werd bij moeders van kinderen met epilepsiechirurgie in de voorgeschiedenis gekenmerkt door snel ergernis ervaren en moeite om woede te beheersen. Het gezinsfunctioneren ervoeren moeders en vaders verschillend: bijna één op de drie moeders vond vooral de communicatie binnen het gezin niet bevredigend, bijna één op de vier vaders vond dat de organisatie van het gezin te wensen overliet. Op een gedragsvragenlijst beoordeelde bijna 50\% (veel meer dan in de testreferentiegroep) van de ouders het gedrag van hun kind als problematisch. De minste gedragsproblemen werden beschreven door ouders van aanvals- en medicatievrije kinderen en door ouders van kinderen met een hemisfe- rectomie in de voorgeschiedenis. Dit laatste kan als volgt verklaard worden: de hemisferectomie heeft bij de meeste kinderen geleid tot aanvals- en medicatievrijheid. Bovendien hadden de ouders hun intellectuele verwachtingen van deze merendeels mentaal geretardeerde kinderen al lang geleden bijgesteld, waardoor de kinderen niet aan onrealistische verwachtingen behoefden te voldoen.

\section{Nieuwe inzichten en conclusies}

Het proefschrift van Olga Braams heeft geleid tot de volgende inzichten:

- Kinderen met refractaire epilepsie lopen achter in de ontwikkeling van basale (waarnemen van gezichtsuitdrukkingen) en hogere (ToM) componenten van sociale cognitie. Hun persoonlijkheidsprofiel maakt hun verhoogde kans op beperkingen in sociaal functioneren begrijpelijk.

- Epilepsiechirurgie veroorzaakt geen kantelpunt in de ontwikkeling van sociale cognitie. Wel ontstaat perspectief op vrijere persoonsontwikkeling wanneer het kind na operatie aanvals- en medicatievrij wordt.

- Vroeg ontstaan en/of lange duur van de epilepsie en niet de lateraliteit of locatie van het epilepsiefocus bepalen mede de achterstand in sociaal functioneren. Dit pleit ervoor om snel na constatering van farmacoresistentie te beslissen of het kind in aanmerking komt voor epilepsiechirurgie.

- Betrekken van het gezin bij behandeling en advisering kan vermijdbare stress en onnodig sociaal isolement voorkomen.

\section{Epilepsie Magazine}

\section{Hebt $\mathrm{u}$ al kennisgemaakt met het voorlichtingsmagazine van het Epilepsiefonds: Epilepsie Magazine?}

Epilepsie Magazine bevat artikelen over wetenschappelijk onderzoek, ervaringsverhalen over mensen met epilepsie en hun omgeving, medische achtergrondinformatie en epilepsienieuws.

\section{Neem nu een abonnement!}

Abonnees ontvangen het kwartaalblad voor $€ 20$,- per jaar. Als $u$ vragen of opmerkingen hebt, kunt $u$ uiteraard bellen of mailen met Annelies Bakker, hoofdredacteur van Epilepsie Magazine: 0306344063 of bakker@epilepsiefonds.nl.

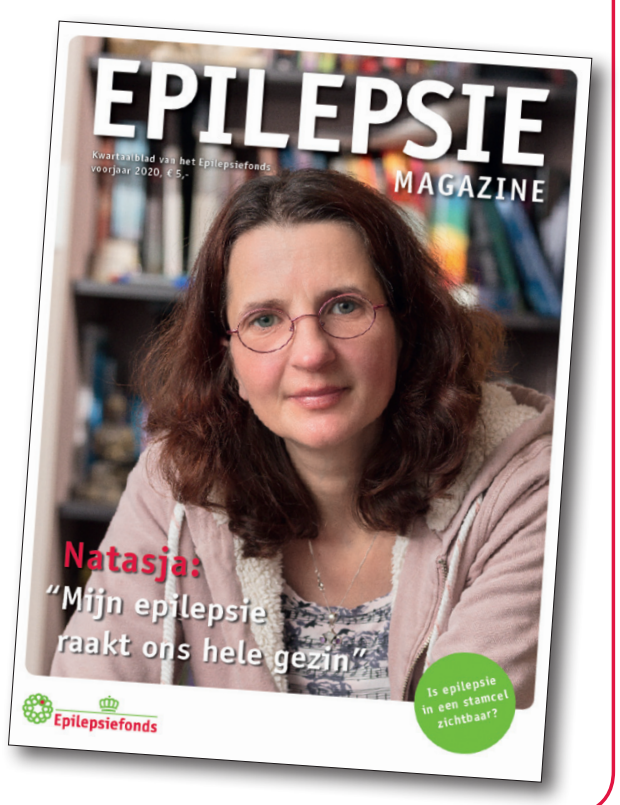

